\title{
PIK3CA hypomethylation plays a key role in activation of the PI3K/AKT pathway in esophageal cancer in Chinese patients
}

\author{
Wei-feng WANG ${ }^{1, \#}$, Yan XIE ${ }^{1, \#}$, Zhi-hua ZHOU², Zheng-hong QIN³ , Jun-chao WU ${ }^{3}$, Jing-kang $\mathrm{HE}^{1, \text { * }}$ \\ ${ }^{1}$ Department of Chest Surgery, First Affiliated Hospital of Soochow University, Suzhou 215006, China; ${ }^{2}$ Department of Pathology, The \\ 101st Hospital of the People's Liberation Army, Wuxi 214000, China; ${ }^{3}$ Laboratory of Aging and Nervous Diseases, Soochow University, \\ Suzhou 215006, China
}

\begin{abstract}
Aim: To investigate the role of PIK3CA oncogene in tumorigenesis and development of esophageal cancer in Chinese patients at the levels of genetic mutation and epigenetics.

Methods: Seventy six esophageal tumor samples and corresponding adjacent normal tissues were collected, and the genomic DNA was extracted. Mutations in the 9th and 20th exons of PIK3CA gene were detected using conventional sequencing. PIK3CA methylation rates in two selected $\mathrm{CpG}$ islands (CpG island 1 and 2 ) were detected using sub-bisulfate modified sequencing. P110 $\alpha$ and pAKT expression levels were detected with Western blotting.

Results: In PIK3CA gene of the tumor tissues, G1633C (E545Q) mutation was detected in the 9th exon with a rate of 3.95\% (3/76), whereas mutation was not found in the 20th exon. Nor mutation did occur in PIK3CA gene of the adjacent normal tissues. The methylation rate of the $\mathrm{CpG}$ island $1 \mathrm{had}$ no significant difference between the tumor and adjacent tissues $(0.77 \% \pm 0.009 \%$ vs $0.89 \% \pm 0.008 \%)$, but the methylation rate of the $\mathrm{CpG}$ island 2 in the esophageal tumors was significantly lower than that in the adjacent tissues $(6.00 \% \pm 2.80 \%$ vs $10.45 \% \pm 5.51 \%)$. Furthermore, the rate of methylation of the CpG island 2 in TNM stage III and IV esophageal cancer $(3.84 \% \pm 2.08 \%)$ was significantly lower than in stage I $(8.52 \% \pm 2.55 \%)$ and stage II $(6.42 \% \pm 2.36 \%)$. PIK3CA gene hypomethylation in esophageal cancer was significantly correlated with high expression of $\mathrm{p} 110 \alpha$.

Conclusion: PIK3CA gene hypomethylation plays a key role in the tumorigenesis and development of esophageal cancer in Chinese patients, while the mutations of PIK3CA gene have little effect on the development of esophageal cancer.
\end{abstract}

Keywords: esophageal cancer; oncogene; PIK3CA; PI3K/AKT pathway; gene mutation; methylation

Acta Pharmacologica Sinica (2013) 34: 1560-1567; doi: 10.1038/aps.2013.163; published online 18 Nov 2013

\section{Introduction}

In China, esophageal cancer is one of the three most common tumors of the gastrointestinal tract, together with gastric and colorectal cancer, and it has the fourth highest mortality rate of all malignancies. The mortality rate due to esophageal cancer was 15.04/100000 in 2004-2005, with rates of 20.46/100000 and $9.38 / 100000$ in males and females, respectively ${ }^{[1]}$. The highest incidence of esophageal cancer occurs in Henan Province, China, and is $81.78 / 100000^{[2]}$. It remains a challenge to give effective therapy for esophageal patients due to the lack of targeted therapeutic drugs. Therefore, there is an urgent

\footnotetext{
\# These authors contributed equally to this work.

* To whom correspondence should be addressed.

E-mail jkhe001@163.com

Received 2013-05-24 Accepted 2013-09-30
}

need to investigate the mechanism of the development of esophageal cancer.

PIK3CA is one of the most common oncogenes in human cancers $^{[3]}$. P110a, the product encoded by the PIK3CA gene, is a catalytic subunit of PI3K. Phosphate kinase (PIK) is a lipid kinase that phosphorylates phosphoinositide and can participate in signal transduction. Based on the phosphorylation sites, the PIKs can be divided into three families: phosphoinositide 3-kinase (PI3Ks), phosphoinositide 4-kinase (PI4Ks), and phosphoinositide 5-kinase (PI5Ks). The PI3Ks are further divided into three classes (I, II, and III) according to subunit structure, regulation and substrate selectivity. The Class I PI3Ks contains the IA and IB subgroups. Class IA PI3K is composed of three catalytic subunits: p110a, p110 $\beta$, and $\mathrm{p} 110 \delta$, and five different regulatory domains: $\mathrm{p} 85 \mathrm{a}, \mathrm{p} 85 \beta$, p85y, p50a, and p55a. These PI3Ks are activated by the cell 
surface receptor-tyrosine kinase. Class I PI3Ks catalyze the formation of phosphatidylinositol-3-phosphate (PIP3). PIP3 combines with the serine/threonine kinases AKT1, AKT2, and AKT3, targets the cell membrane and is then activated by 3-phosphoinositide-dependent protein kinase 1 (PDK1). After activation, AKT displays a wide range of biological effects through its series of target proteins, such as mTOR, BAD, caspase 9, tuberin, GSK3 $\beta$, MDM2, p21, FKHR-L1 ${ }^{[4-11]}$, and several forkhead transcription factors. These effects are related to the regulation of cell proliferation and cell survival, and the control of cell movement. PIK3CA overexpression, caused by changes in the PIK3CA gene, enhances PI3K catalytic activity, while the intracellular PI3K/AKT pathway maintains an abnormal activation status and is responsible for malignant transformation.

Mutations of PIK3CA exist in approximately $30 \%$ of human solid tumors. The tumors that most frequently display the PIK3CA mutation include endometrial, breast, colon, and skin cancers $^{[3]}$. According to the literature, PIK3CA mutation rates in esophageal cancer are lower in Japanese and Australian patients ${ }^{[12,13]}$. We found no experimental data on PIK3CA methylation in the published literature. We aimed to investigate the relationship between PIK3CA and esophageal cancer with regard to mutation and methylation.

\section{Materials and methods}

\section{Patients and pathologic specimens}

All 76 cases of esophageal cancer underwent surgery in the Department of Cardiothoracic Surgery of the First Affiliated Hospital of Soochow University between May 2010 and May 2011. The pathologic specimens were processed within $10 \mathrm{~min}$ of surgical resection. All adjacent tissues were removed from surgical sites at least $5 \mathrm{~cm}$ from the tumor margins. The specimens were immediately frozen in liquid nitrogen and stored at $-80^{\circ} \mathrm{C}$. The patients had not received any preoperative therapy, including chemotherapy, radiotherapy and biotherapy. All patients underwent radical resection and were confirmed by pathological diagnosis. Two patients had adenocarcinoma, and the rest had squamous cell carcinomas. This study was approved by our institutional ethics committee.

\section{Genomic DNA extraction}

Genomic DNA was extracted from 76 frozen fresh tissues using a UNIQ-10 Genomic DNA Purification Kit (Shanghai Sangon Biotech Co, Ltd, Shanghai, China) according to the manufacturer's instructions.

\section{Detection of PIK3CA mutation}

We employed conventional sequencing as follows. PIK3CA 9th exon forward primer sequence: $5^{\prime}$-gttgttggctaacttcagcag- $3^{\prime}$; reverse primer sequence: 5' -attccaataggtatggtaaaaacatg-3'. PIK3CA 20th exon forward primer sequence: $5^{\prime}$-ctcaatgatgcttggctctg-3'; reverse primer sequence: 5' -gaaagctcactctggattcca-3'. PCR was performed in a mixture containing $2 \mu \mathrm{L}$ of $10 \times$ Taq buffer, $1.2 \mu \mathrm{L}$ of $25 \mathrm{mmol} / \mathrm{L} \mathrm{MgCl}_{2}, 1.6 \mu \mathrm{L}$ of $\mathrm{dNTP}, 0.4 \mu \mathrm{L}$ each of $10 \mathrm{mmol} / \mathrm{L}$ solutions of the forward primer and the reverse primer, $0.2 \mu \mathrm{L}$ of a $5 \mathrm{U} / \mu \mathrm{L}$ solution of Taq enzyme, 0.2 $\mu \mathrm{L}$ of DNA, and double distilled water to a volume of $20 \mu \mathrm{L}$. We performed Touch-Down PCR for amplification: $10 \mathrm{~min}$, $95^{\circ} \mathrm{C}$ denaturation, $95^{\circ} \mathrm{C}$ for $30 \mathrm{~s}, 65^{\circ} \mathrm{C}$ (each cycle decreasing $1^{\circ} \mathrm{C}$ ) for $30 \mathrm{~s}, 72^{\circ} \mathrm{C}$ for $30 \mathrm{~s}, 11$ cycles of $95^{\circ} \mathrm{C}, 54^{\circ} \mathrm{C}, 72^{\circ} \mathrm{C}$, each $30 \mathrm{~s}, 24$ cycles of $72^{\circ} \mathrm{C}$, for an additional $10 \mathrm{~min}$. The PCR products were directionally sequenced using an ABI 3730 XL instrument at the Beijing Genomics Institute after verification of amplification by $1 \%$ agarose gel electrophoresis.

\section{Detection of PIK3CA methylation}

PIK3CA methylation has a greater effect on esophageal cancer than PIK3CA mutations. PIK3CA hypomethylation is a key mechanism of activation of the PI3K/AKT pathway in esophageal cancer. So we detected the PIK3CA methylation in patients with esophageal cancer.

We conducted bisulfite sequencing PCR (BSP). Bisulfite DNA conversion was performed according to the manufacturer's instructions included with the EpiTect Bisulfite Kit (Qiagen, Duesseldorf, Germany). A $5 \mu \mathrm{g}$ sample of purified DNA was brought to a total volume of $140 \mu \mathrm{L}$. The bisulfite reactions were mixed thoroughly, and the tubes were placed at room temperature. Bisulfite DNA conversion was performed with a thermal cycler as follows: denaturation for $5 \mathrm{~min}$ at $95^{\circ} \mathrm{C}$, incubation for $25 \mathrm{~min}$ at $60^{\circ} \mathrm{C}$; denaturation for $5 \mathrm{~min}$ at $95^{\circ} \mathrm{C}$, incubation for $85 \mathrm{~min}$ at $60^{\circ} \mathrm{C}$; denaturation for $5 \mathrm{~min}$ at $95^{\circ} \mathrm{C}$, incubation for $85 \mathrm{~min}$ at $60^{\circ} \mathrm{C}$; hold at $20^{\circ} \mathrm{C}$. After the bisulfite conversion was complete, purified bisulfite-treated DNA was used as a template for PCR using HotStar Taq DNA polymerase (Qiagen, Duesseldorf, Germany) with specific primers. The PCR products were separated on 1.5\% agarose gels and purified using the AxyPrep Gel Extraction Kit (Axygen, Tewksbury, MA, USA). The purified DNA fragments were ligated into the $\mathrm{pGEM}^{\circledR}$-T vector systems (Promega, Madison, WI, USA) and transformed into TOP10 competent cells (Invitrogen, Grand Island, NY, USA) for further replication. Correct recombinants were screened using the IPTG/ $\mathrm{x}-\mathrm{Gal}$ system, and the plasmids were extracted and sequenced using an ABI 3730 XL.

Universal primer sequences: P2: 5'-GTAAAACGACGGCCAGT-3', P4: 5' -AGCGGATAACAATTTCACACAGGA-3' . CpG island 1 former primers sequence: 5'-AAAGGATTGTAGAGGGTTGTGAT-3', reverse primers sequence: 5'-AAAAACAAAACCTACAATCCCC-3'; CpG island 2 former primers sequence: 5'-TTTGGAAATAAAAGGAAAAAAAAAT-3', reverse primers sequence: 5'-TCRAAACTCTTCCAAACTCC $-3^{\prime}$. PCR program: $95^{\circ} \mathrm{C}$ denaturation for $5 \mathrm{~min}$, followed by $95^{\circ} \mathrm{C}, 64^{\circ} \mathrm{C}$, and $72^{\circ} \mathrm{C}$ each for $30 \mathrm{~s}$ for 50 cycles, followed by $72^{\circ} \mathrm{C}$ for $10 \mathrm{~min}$.

The amplification products were sequenced by Shanghai HaoYu Biotechnology Co, Ltd (Shanghai, China). We used chrome $\mathrm{AC} / \mathrm{DC}$ to observe the $\mathrm{ABI}$ peak figure files and to determine whether these peaks represented singlebase mutations or base deletions. Statistical significance was determined. BiQ Analyzer software, version 2.0 (developed by Max-Planck-Institute for Informatics and Saarland Univer- 
sity, Saarbrucken, Germany)was used to analyze five cloning sequences and obtain a SEQ file for each sample. The total numbers of unmethylated CG sites and methylation CpG loci were tallied, respectively. Finally, the methylation rate was calculated.

\section{Determination of $\mathrm{pAKT}$ and $\mathrm{p} 110 \alpha$ expression by Western blotting}

We employed a standard Western blot procedure. The $\beta$-actin protein was selected as an internal reference (rabbit anti-Item AA128-1).

Taq DNA polymerase and primers corresponding to the 9th and 20th exon of PIK3CA were purchased from the Shanghai Sangon Biotech Co Ltd (Shanghai, China). DNA markers were purchased from Fermentas Co (Pittsburgh, PA, USA). The p110a monoclonal antibody (PI3 Kinase of p110a [C73F8] rabbit $\mathrm{mAb} \# 4249$, diluted at 1:400) and the pAKT monoclonal antibody (phospho-Akt [Ser473] [D9E] XP Rabbit mAb \#4060, diluted at 1:50) were purchased from Cell Signaling Technology Co for Western blot experiments. The secondary antibody was HRP-labeled Goat Anti-Rabbit IgG $(\mathrm{H}+\mathrm{L})$, diluted at 1:1000 (Beyotime Co, Nantong, China). PVDF membrane was purchased from American Millipore Co (Billerica, MA, USA), and the primers and dNTPs were purchased from the Shanghai Sangon Biotech Co, Ltd (Shanghai, China).

We used Quantity One software (Bio-Rad, Hercules, CA, USA)to test each sample's gray scale values of $\beta$-actin and target protein bands. According to the data presented above, we calculated the relative content of the target protein and compared the samples to determine the actual change in the level of the target protein between samples. We found that the gray scale values of the target protein were $50 \%$ higher in esophageal cancer than in the adjacent tissues. There was no difference in expression, with positive expression numbers of pAKT and p110a, respectively.

\section{Statistical analysis}

All data were categorized using Excel 2003. Statistical analysis was performed using SPSS 18.0 statistical software. All experimental data are expressed as the mean plus or minus the standard deviation. Comparisons of variable data were performed with the chi-squared or Fisher's exact test (double sided), Spearman correlation analysis, as well as the Student's $t$-test and ANOVA for single comparisons. A $P$-value of less than 0.05 was considered statistically significant.

\section{Results}

PIK3CA mutation in esophageal cancer patients

We detected a G1633C (E545Q) mutation in the 9th exon of PIK3CA in 3.95\% (3/76) of the esophageal squamous cell carcinomas. No mutations were found in the 20th exon of PIK3CA in the tumor tissues or the adjacent tissues. The PIK3CA mutation is a point mutation ${ }^{[12]}$ that occurs during the middle to late stage of esophageal squamous carcinoma (Figure 1 and 2).
We detected the mutations A1634C, T1659C, and G1658 in all tumors and adjacent tissues. These mutations originate from homologous genes (22 chromosome NW NT 011519.10 and $011519.10,97 \%$ homology) and were also detected by Tanaka ${ }^{[14]}$, Liu Peng ${ }^{[15]}$, and Wanglong Qiu ${ }^{[16]}$.

\section{PIK3CA methylation}

We used 32 samples of esophageal tumor tissue and the corresponding adjacent tissues for the methylation determination.

MethPrimer software (The Li Lab, San Francisco, CA, USA) was used to predict the human PIK3CA gene promoter regions, and we selected two $\mathrm{CpG}$ islands rich in CG (CpG island 1: -800 bp to $-400 \mathrm{bp}, \mathrm{CpG}$ island 2: -250 bp to 50 $\mathrm{bp}$ ). Five PCR clones from each specimen were selected for sequencing (Figure 3 and 4 ).

Statistical analysis showed that the rates of $\mathrm{CpG}$ island 1 methylation in the tumor $(0.77 \% \pm 0.0089 \%)$ and adjacent tissues $(0.89 \% \pm 0.0084 \%)$ were low, and there was not statistically significant difference between them $(t=-0.553, P=0.582)$. The rate of CpG island 2 methylation $(6.00 \% \pm 2.80 \%)$ was significantly lower in the tumor tissues than in the adjacent tissues $(10.45 \% \pm 5.51 \% ; t=-4.067, P=0.0001)$ (Figure 5).

The relationship between PIK3CA hypomethylation and demographic features in esophageal cancer

We analyzed the relationship between PIK3CA methylation and the demographic characteristics of patients with esophageal cancer. There was a significant difference in the average methylation rate at Stage III and IV $(3.84 \% \pm 2.08 \%)$ compared with Stage I $(8.52 \% \pm 2.55 \%)$ and II $(6.42 \% \pm 2.36 \%)\left(P_{\mathrm{I}-\mathrm{III}}=0.001\right.$, $\left.P_{\text {II- III }}=0.01\right)$. There were no other statistically significant differences (Table 1).

Table 1. The correlation between PIK3CA hypomethylation and demographic features of esophageal cancer patients.

\begin{tabular}{|c|c|c|c|}
\hline & $n$ & $\begin{array}{l}\text { Average methylation } \\
\text { rate (\%) }\end{array}$ & $P$-value \\
\hline Total number & 32 & $6.00 \pm 2.80$ & - \\
\hline Age $\leq 45$ years & 8 & $5.77 \pm 2.51$ & \multirow{2}{*}{$t=-0.845, P=0.405$} \\
\hline$>45$ years & 24 & $6.74 \pm 3.63$ & \\
\hline Male & 23 & $5.79 \pm 2.63$ & \multirow{2}{*}{$t=-0.689, P=0.496$} \\
\hline Female & 9 & $6.56 \pm 3.30$ & \\
\hline Tumor size $\leq 3 \mathrm{~cm}$ & 5 & $6.94 \pm 4.53$ & \multirow{3}{*}{$F=0.318, P=0.730$} \\
\hline $3-5 \mathrm{~cm}$ & 23 & $5.85 \pm 2.23$ & \\
\hline$\geq 5 \mathrm{~cm}$ & 4 & $5.77 \pm 3.93$ & \\
\hline Positive lymph nodes & 14 & $5.49 \pm 2.76$ & \multirow{2}{*}{$t=-0.917, P=0.366$} \\
\hline Negative lymph nodes & 18 & $6.41 \pm 2.84$ & \\
\hline TNM stage I & 6 & $8.52 \pm 2.55$ & \\
\hline TNM stage II & 16 & $6.42 \pm 2.36$ & $P_{1-I I I}=0.001$ \\
\hline TNM stage IIIa+IIIb, IV & 10 & $3.84 \pm 2.08^{*}$ & $P_{\| 1-\mid I I}=0.01$ \\
\hline
\end{tabular}

Comparisons of single samples were performed with the Student's $t$-test and ANOVA test. *, Stage III and IV specimens were analyzed in one category. 

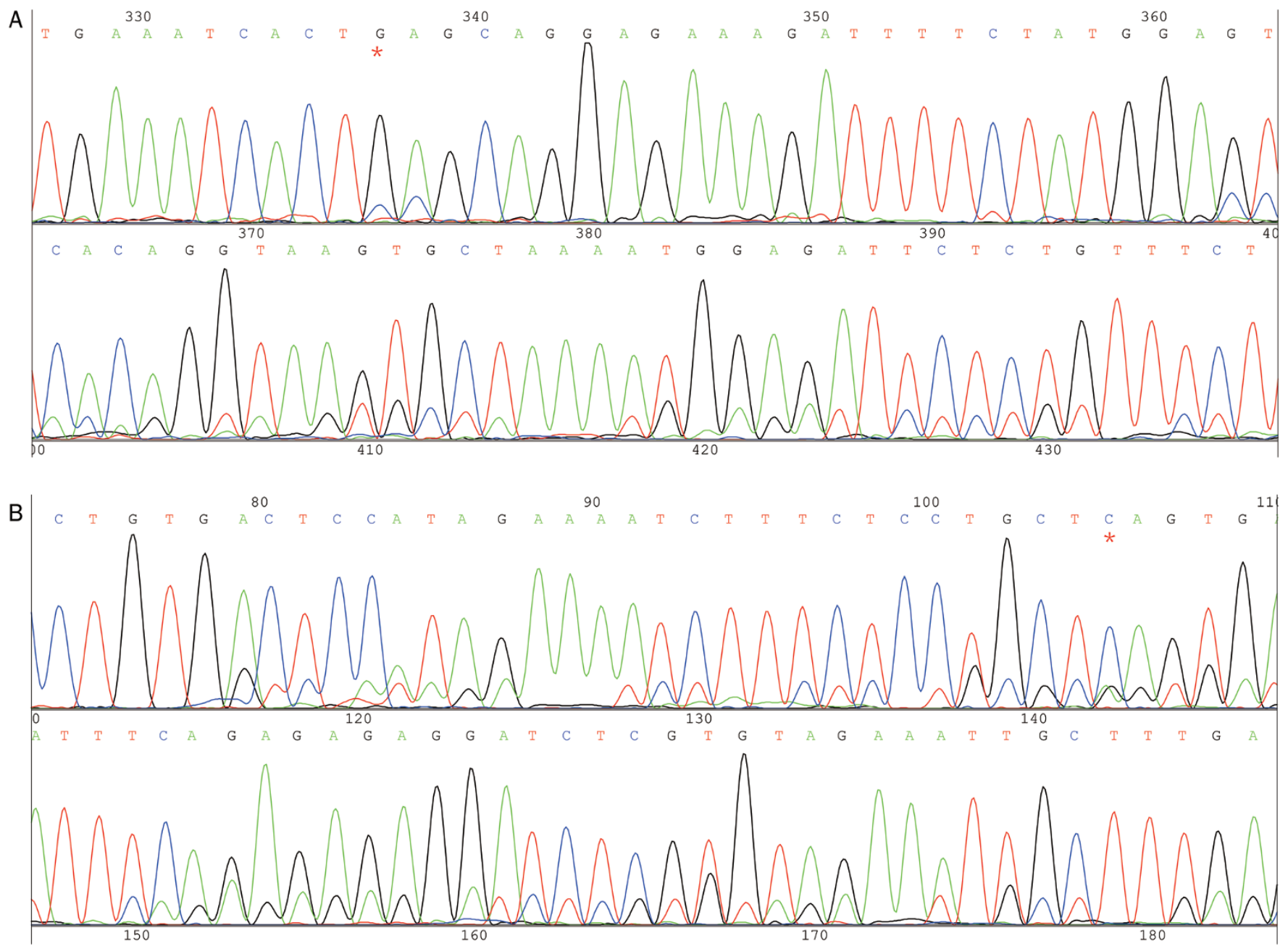

Figure 1. G1633C (E545Q) mutation of 9th exon in PIK3CA. (A) Former sequence of the 9th exon, G1633C (E545Q). (B) Reverse sequence of the 9th exon, G1633C (E545Q). The red "*" represent G1633C.

\section{Expression of $\mathrm{p} 110 \alpha$ and $\mathrm{pAKT}$ by Western blotting}

We used Quantity One software (Bio-Rad, Hercules, CA, USA) to obtain the gray scale values of all bands. We calculated the relative gray scale values (target band gray scale value/internal control gray scale value) and performed statistical analysis (Figure 6).

We demonstrated that p110a expression was significantly higher in the tumor tissues versus the adjacent tissues (0.14 \pm 0.09 vs $0.07 \pm 0.05, P=0.015)$. Likewise, $\mathrm{pAKT}$ expression was also higher in the tumor tissues versus the adjacent tissues $(0.11 \pm 0.07$ vs $0.06 \pm 0.04 ; P=0.023)$ (Figure 7).

Correlation between PIK3CA hypomethylation and the expression of $p 110 \alpha$ and $p A K T$ in esophageal tumor tissue and the adjacent tissue

We demonstrated that the methylation rate in the group of $\mathrm{p} 110 \mathrm{a}(-)$ was significantly higher than in the group of $\mathrm{p} 110 \mathrm{a}(+)[(7.92 \pm 3.09) \%$ vs $(5.26 \pm 2.34) \%, P=0.013]$. There were no statistically significant differences between the group
Table 2. The correlation between PIK3CA methylation rate and PIK3CA proteins expression in esophageal cancer. ${ }^{\mathrm{b}} \mathrm{P}<0.05$.

\begin{tabular}{lccc}
\hline & Case & Average rate of methylation & $P$ \\
\hline $\begin{array}{l}\text { p110 } \alpha \\
+\end{array}$ & 23 & $(5.26 \pm 2.34) \%$ & \\
- & 9 & $(7.92 \pm 3.09) \%$ & $P=0.013^{\mathrm{b}}$ \\
pAKT & & & \\
+ & 16 & $(5.49 \pm 2.62) \%$ & $P=0.306$ \\
- & 16 & $(6.52 \pm 2.96) \%$ & \\
\hline
\end{tabular}

of pAKT $(+)$ and the group of pAKT $(-)[(5.49 \pm 2.62) \%$ vs $6.52 \pm 2.96) \%, P=0.306$ ] (Table 2).

\section{Discussion}

PIK3CA mutation in esophageal cancer occurs in the middle and advanced stages

PIK3CA mutations occur in approximately 30\% of human 

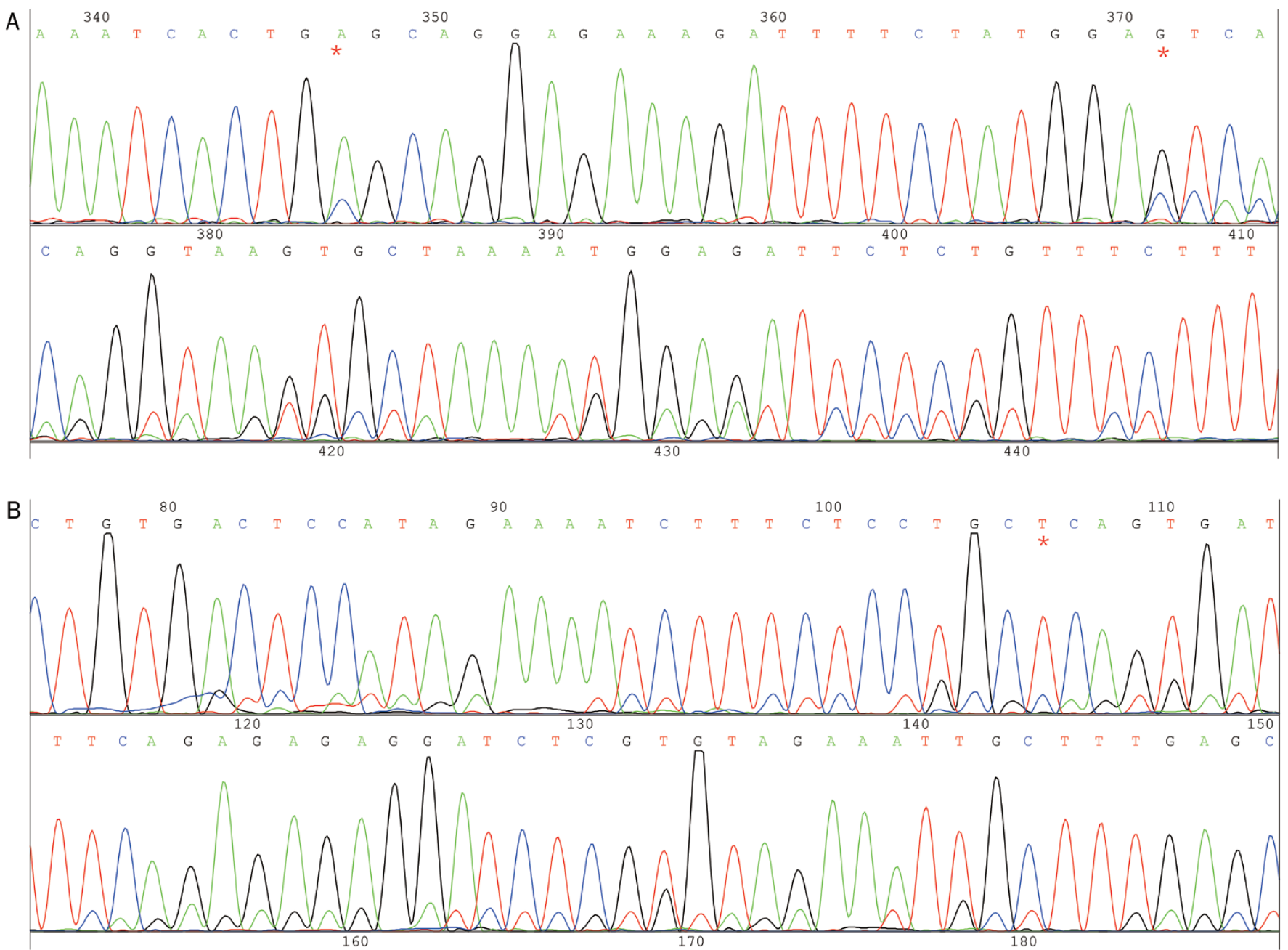

Figure 2. The mutation of A1634C, T1659C, and G1658 of the 9th exon. (A) Former sequence. (B) Reverse sequence. The red "*" represents A1634C, T1659C, and G1658.

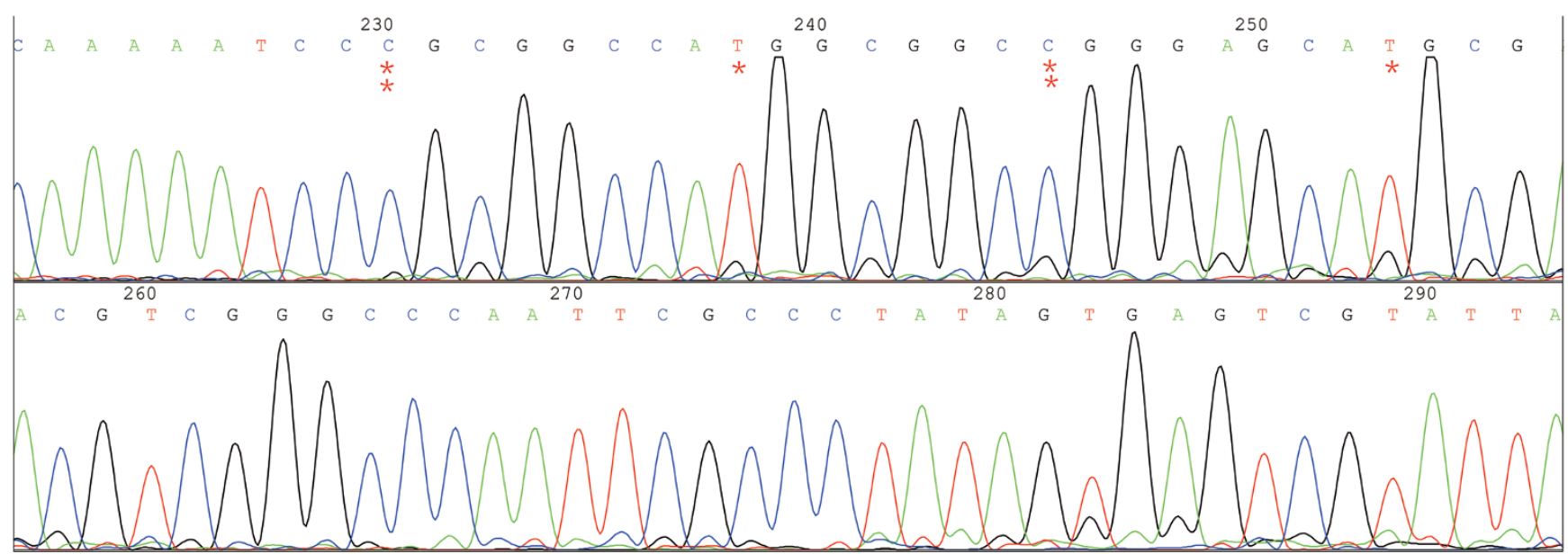

Figure 3. The methylation clone sequencing of specimen L1 CpG island 2. The red "**" represents methylated Cs; red "*" represents unmethylated Cs.

solid tumors. The cancers that most frequently exhibit mutations in PIK3CA are endometrial, breast, colon, and skin can- cers $^{[3]}$. The PIK3CA mutation rates vary from $4 \%-52 \%$ in different types of cancer ${ }^{[17-27]}$. In colon cancer, the PIK3CA muta- 

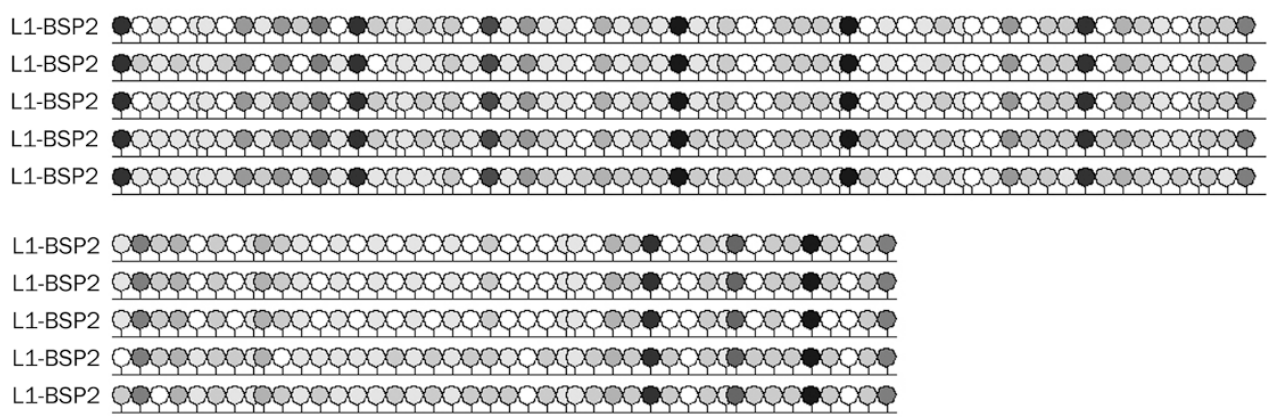

Figure 4. A black-white circle figure of specimen L1 methylation. A black circle and a white circle indicates a methylated Cs and a unmethylated Cs, respectively.

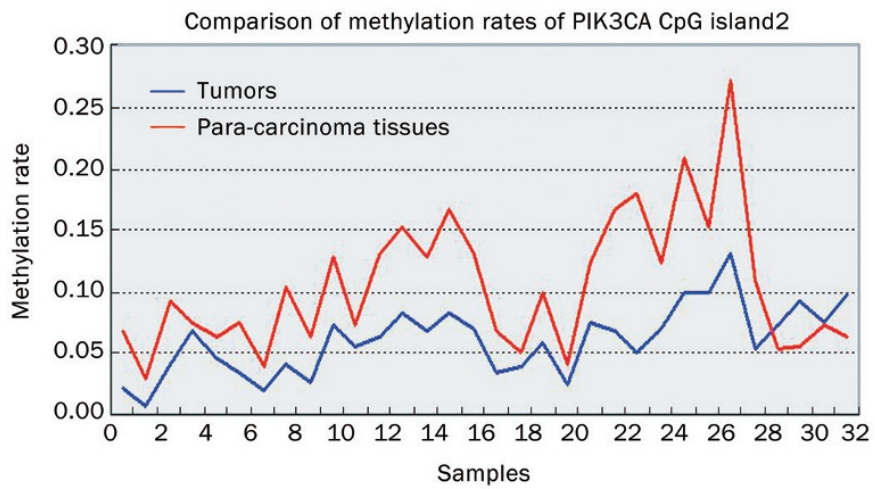

Figure 5. Comparison of methylation rates PIK3CA CpG island 2 in 32 esophageal tumor and adjacent tissue samples. The red line represents adjacent tissue samples, the blue line represents tumor.

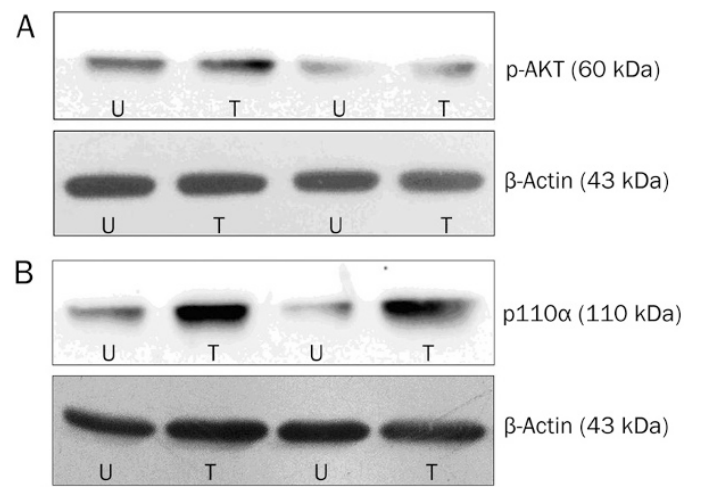

Figure 6. The expression of $\mathrm{pAKT}(\mathrm{A})$ and $\mathrm{p} 110 \alpha(\mathrm{B})$ in tumor and adjacent tissues. $T$ indicates tumors, $U$ indicates normal tissues or adjacent tissues.

tion rates are over 30\% and are the highest among all gastrointestinal tumors ${ }^{[28,29]}$, followed by gastric cancer, with mutation rates that vary from $4 \%-25 \%[30,31]$. In esophageal cancer, the PIK3CA mutation rate is as high as $21 \%^{[32]}$. Of these mutations, $80 \%$ are clustered in two previously reported "hotspots" or high-risk regions of the 9th and 20th exons, which correspond to the accessory (helical) and catalytic domains of
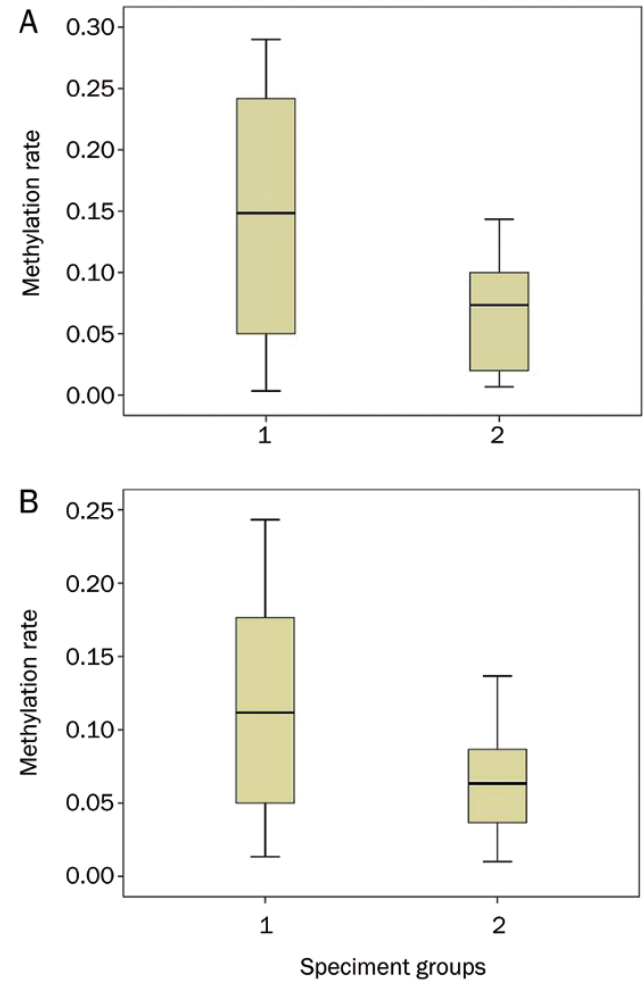

Figure 7. Comparison of methylation rates of $p 110 \alpha(A)$ and $p A K T(B)$ between tumor tissues and normal or adjacent tissues. "1" indicates tumors and "2" indicates normal tissues or adjacent tissues.

PIK3CA ${ }^{[3]}$. Non-random hypermutation plays a significant role in tumor development. The main types of mutation are E545K (G1633A) and E545Q (G1633C) ${ }^{[33]}$, E542K, and E545D ${ }^{[12]}$, and $\mathrm{A} 1634 \mathrm{C}^{[13]}$ in the 9 th exon and H1047R in the 20th exon ${ }^{[34]}$. Our study focused on these two exons, and we found that all of the PIK3CA mutations in our samples were G1633C. This point mutation occurred at a rate that was lower than reported in other studies. We found no substitutions, truncations, or frameshift mutations ${ }^{[12,35]}$.

Thus far, the role of PIK3CA mutations in esophageal carcinogenesis (early stage) or the promotion of malignancy (advanced stages) has not been established. Some investi- 
gators speculate that PIK3CA mutations may play a role in early esophageal tumors and subsequent carcinogenesis ${ }^{[12]}$. The role of PIK3CA in gastric cancer has been established; the lack of associated symptoms or pathology suggests that PIK3CA mutations may occur early in cancer development ${ }^{[36]}$. Yardena et al found that PIK3CA mutations in early colon cancer occurred at a much lower rate than in middle-late stage cancer; thus, a relationship between PIK3CA mutations and carcinogenesis was proposed ${ }^{[35]}$. Other investigators have demonstrated that PIK3CA mutations occur almost exclusively in invasive tumors, with upstream gene mutations often occurring in early and late tumors, suggesting that PIK3CA mutation is a late event ${ }^{[37]}$. We demonstrated that esophageal PIK3CA mutations only occurred in the later TNM stages (IIIa and IIIb). While there is abundant evidence that PIK3CA mutations promote tumorigenesis by activation of the PI3K/ AKT pathway in other cancers ${ }^{[38,39]}$, we did not find an association between p110a and pAKT expression in the PI3K/AKT pathway. Therefore, the PIK3CA mutation may occur late in esophageal cancer. We found no evidence to support that these mutations promote malignant degeneration. Additional studies are required to determine the role of PIK3CA in the development of esophageal cancer, including investigations with a broader range of detection of mutations and studies of additional esophageal cancer cases.

PIK3CA hypomethylation is closely related to the activation of the $\mathrm{PI}$ KK/AKT pathway and may be a key mechanism in esophageal carcinogenesis

DNA methylation is an important mode of epigenetic modification, and it occurs in a variety of context throughout the mammalian genome. CpG occurs in either a dispersed (scattered) or a highly concentrated ("CpG island") pattern. CpG islands occur in up to $1 \%$ of genomic DNA, and they are present at the $5^{\prime}$ ends of the regulatory regions in all housekeeping genes. $\mathrm{CpG}$ islands often cover the promoter region and are found within the first exon. Hypomethylation is another abnormal form of DNA methylation in cancer. Hypermethylation of a suppressor gene and hypomethylation of oncogenes may coexists in cancer, which can affect the stability of the genome and the normal expression of gene involved in cell proliferation and differentiation. These aberrations can cause cells to lose control of their normal processes, promoting the formation and development of tumors. In 1983, Feinberg and Vogelstein found that the growth hormone genes, a-globin and $\beta$-globin, are highly methylated in normal tissues but not in cancer tissues ${ }^{[40]}$. Universal hypomethylation of the entire genome and hypomethylation of specific sites in the oncogene promoter region increases cancer risk ${ }^{[41]}$. The lower degree of methylation in proto-oncogenes is significantly related to invasiveness $^{[42,43]}$. There are no reports about PIK3CA methylation in esophageal cancer to date. The PIK3CA oncogene should be hypomethylated in esophageal cancer and hypermethylated in adjacent or normal tissues. We found that the PIK3CA methylation rate in esophageal cancer was significantly lower than in the adjacent tissues, correlating with higher TNM stag- ing.

In addition, our data show that PIK3CA methylation negatively correlates with p110a expression, but not pAKT expression. That is to say, the status of PIK3CA hypomethylation in esophageal cancer regulates its coding expression. Meanwhile, other inhibitory factors may be reduced, resulting in stimulation of the expression of p110a. The reason for the absence of a correlation with the downstream target moleculepAKT, based on our understanding of the PI3K/AKT signaling pathway, we proposed that $\mathrm{pAKT}$ is the terminal target molecule of multiple signaling pathways, and its expression level is influenced by many factors. Therefore, PIK3CA hypomethylation is not the decisive factor determining the high level of pAKT expression.

Our previous experiments ${ }^{[44]}$ have demonstrated that PI3K/ AKT activation is closely related to the progression of esophageal cancer. Thus, we believe that PIK3CA hypomethylation is significantly related to the development of esophageal cancer. PIK3CA hypomethylation may be part of the activation mechanism in the PI3K/AKT pathway.

We only selected two CpG islands based on the CpGplot program. The full effects of PIK3CA methylation may not be completely apparent due to missing methylation sites. In our future experiments, we will obtain additional samples and examine other $\mathrm{CpG}$ islands. Hypermethylation of PTEN, which is related to the PI3K/AKT pathway, may be carcinogenic in esophageal cancer. Whether there is a link between PTEN hypermethylation and PIK3CA hypomethylation remains unknown and requires further investigation.

\section{Acknowledgements}

This study was supported by the project of the Jiangsu Province's Key Provincial Talents Program (RC2011112).

\section{Author contribution}

Jing-kang HE and Yan XIE designed the research; Wei-feng WANG and Zhi-hua ZHOU performed the research; Wei-feng WANG wrote the manuscript; Zheng-hong QIN and Jing-kang HE edited the manuscript; Wei-feng WANG and Jun-chao WU analyzed the data.

\section{References}

1 Chinese Center for Disease Control and Prevention, China Health statistical Summary 2012. http://www.chinacdc.cn/tjsj/ gjwstjsj/201206/W020120608368277572334.pdf, 2012.

2 Sun XB, Liu ZC, Liu SZ, Li BY, Dai DX, Quan PL, et al. Descriptive analysis of incidence and time trends of esophageal and gastric cancers in Linzhou city. Chin J Oncol 2007; 10: 764-7.

3 Samuels Y, Waldman T. Oncogenic mutations of PIK3CA in human cancers. Curr Top Microbiol Immunol 2010; 347: 21-41.

4 Inoki K, Corradetti MN, Guan KL. Dysregulation of the TSC-mTOR pathway in human disease. Nat Genet 2005; 37: 19-24.

5 Datta SR, Dudek H, Tao X, Masters S, Fu H, Gotoh Y, et al. Akt phosphorylation of BAD couples survival signals to the cellintrinsic death machinery. Cell 1997; 91: 231-41.

6 Cardone MH, Roy N, Stennicke HR, Salvesen GS, Franke TF, Stanbridge $\mathrm{E}$, et al. Regulation of cell death protease caspase- 9 by 
phosphorylation. Science 1998; 282: 1318-21.

7 Cross DA, Alessi DR, Cohen P, Andjelkovich M, Hemmings BA. Inhibition of glycogen synthase kinase-3 by insulin mediated by protein kinase B. Nature 1995; 378: 785-9.

8 Zhou BP, Liao Y, Xia W, Zou Y, Spohn B, Hung MC. HER-2/neu induces p53 ubiquitination via Akt-mediated MDM2 phosphorylation. Nat Cell Biol 2001; 3: 973-82.

9 Rossig L, Jadidi AS, Urbich C, Badorff C, Zeiher AM, Dimmeler S. Aktdependent phosphorylation of p21(Cip1) regulates PCNA binding and proliferation of endothelial cells. Mol Cell Biol 2001; 21: 5644-57.

10 Brunet A, Bonni A, Zigmond MJ, Lin MZ, Juo P, Hu LS, et al. Akt promotes cell survival by phosphorylating and inhibiting a Forkhead transcription factor. Cell 1999; 96: 857-68.

11 Rena G, Guo S, Cichy SC, Unterman TG, Cohen P. Phosphorylation of the transcription factor forkhead family member FKHR by protein kinase B. J Biol Chem 1999; 274: 17179-83.

12 Phillips W, Russell SE, Ciavarella ML. Mutation analysis of PIK3CA and PIK3CB in esophageal cancer. Int J Cancer 2006; 118: 2644-6.

13 Akagi I, Miyashita M, Makino H, Nomura T, Hagiwara N, Takahashi $\mathrm{K}$, et al. Overexpression of PIK3CA is associated with lymph node metastasis in esophageal squamous cell carcinoma. Int J Oncol 2009; 34: 767-75.

14 Tanaka Y, Kanai F, Tada M, Asaoka Y, Guleng B, Jazag A, et al. Absence of PIK3CA hotspot mutations in hepatocellular carcinoma in Japanese patients. Oncogene 2006; 25: 2950-2.

15 Liu P, Li DJ, Qin HD, Zhang RH, Chen LZ, Zeng YX. Screening for mutations in the hotspot mutation regions of PIK3CA gene in nasopharyngeal carcinama. Chin J Cancer 2007; 26: 15-20.

16 Qiu W, Schönleben F, Li X, Ho DJ, Close LG, Manolidis S, et al. PIK3CA mutations in head and neck squamous cell carcinoma. Clin Cancer Res 2006; 12: 1441-6.

17 Rudd ML, Price JC, Fogoros S, Godwin AK, Sgroi DC, Merino MJ, et al. A unique spectrum of somatic PIK3CA (p110 $\alpha$ ) mutations within primary endometrial carcinomas. Clin Cancer Res 2011; 17: 133140.

18 Lee JW, Soung YH, Kim SY, Lee HW, Park WS, Nam SW, et al. PIK3CA gene is frequently mutated in breast carcinomas and hepatocellular carcinomas. Oncogene 2005; 24: 1477-80.

19 Wang Y, Helland A, Holm R, Kristensen GB, Børresen-Dale AL. PIK3CA mutations in advanced ovarian carcinomas. Hum Mutat 2005; 25 : 322-7.

20 Abubaker J, Bavi P, Al-Haqawi W, Jehan Z, Munkarah A, Uddin S, et al. PIK3CA alterations in middle eastern ovarian cancers. Mol Cancer 2009; 8: 51-63.

21 Hartmann C, Bartels G, Gehlhaar C, Holtkamp N, Deimling A. PIK3CA mutations in glioblastoma multiforme. Acta Neuropathol 2005; 109: 639-42.

22 Kita D, Yonekawa Y, Weller M, Ohgaki H. PIK3CA alterations in primary (de novo) and secondary glioblastomas. Acta Neuropathol 2007; 113: 295-302.

23 Levine DA, Bogomolniy F, Yee CJ, Lash A, Barakat RR, Borgen PI, et al. Frequent mutation of the PIK3CA gene in ovarian and breast cancers. Clin Cancer Res 2005; 11: 2875-8.

24 Campbell IG, Russell SE, Choong DY, Montgomery KG, Ciavarella ML, Hooi CS, et al. Mutation of the PIK3CA gene in ovarian and breast cancer. Cancer Res 2004; 64: 7678-81.

25 Qiu WL, Schönleben F, Li XJ, Ho DJ, Close LG, Manolidis S, et al. PIK3CA mutations in head and neck squamous cell carcinoma. Clin Cancer Res 2006; 12: 1441-6.

26 Kozaki K, Imoto I, Pimkhaokham A, Hasegawa S, Tsuda H, Omura K, et al. PIK3CA mutation is an oncogenic aberration at advanced stages of oral squamous cell carcinoma. Cancer Sci 2006; 97: 1351-8.

27 Yamamoto H, Shigematsu H, Nomura M, Lockwood WW, Sato M, Okumura N, et al. PIK3CA mutations and copy number gains in human lung cancers. Cancer Res 2008; 68: 6913-21.

28 Samuels Y, Wang Z, Bardelli A, Silliman N, Ptak J, Szabo S, et al. High frequency mutations of the PIK3CA gene in human cancers. Science 2004; 304: 554.

29 Kuo KT, Mao TL, Jones S, Veras E, Ayhan A, Wang TL, et al. Frequent activating mutations of PIK3CA in ovarian clear cell carcinoma. Am J Pathol 2009; 174: 1597-601.

30 Li VS, Wong CW, Chan TL, Chan AS, Zhao W, Chu KM, et al. Mutations of PIK3CA in gastric adenocarcinoma. BMC Cancer 2005; 5: 29.

31 Barbi S, Cataldo I, De Manzoni G, Bersani S, Lamba S, Mattuzzi S, et al. The analysis of PIK3CA mutations in gastric carcinoma and metanalysis of literature suggest that exon-selectivity is a signature of cancer type. J Exp Clin Cancer Res 2010; 29: 32-6.

32 Shigaki H, Baba Y, Watanabe M, Murata A, Ishimoto T, Iwatsuki M, et al. PIK3CA mutation Is associated with a favorable prognosis among patients with curatively resected esophageal squamous cell carcinoma. Clin Cancer Res 2013; 19: 2451-9.

33 Mori R, Ishiguro H, Kimura M, Mitsui A, Sasaki H, Tomoda K, et al. PIK3CA mutation status in Japanese esophageal squamous cell carcinoma. J Surg Res 2008; 145: 320-6 .

34 Maeng $\mathrm{CH}$, Lee J, van Hummelen P, Park SH, Palescandolo E, Jang $J$, et al. High-throughput genotyping in metastatic esophageal squamous cell carcinoma identifies phosphoinositide-3-kinase and BRAF mutations. PLoS One 2012; 7: e41655.

35 Samuels $\mathrm{Y}$, Velculescu VE. Oncogenic mutations of PIK3CA in human cancers. Cell Circle 2004; 3: 17-9.

36 Barbi S, Cataldo I, De Manzoni G, Bersani S, Lamba S, Mattuzzi S, et al. The analysis of PIK3CA mutations in gastric carcinoma and metanalysis of literature suggest that exon-selectivity is a signature of cancer type. J Exp Clin Cancer Res 2010; 29: 32-6.

37 Oda K, Okada J, Timmerman L, Rodriguez-Viciana P, Stokoe D, Shoji $\mathrm{K}$, et al. PIK3CA cooperates with other phosphatidylinositol 3-kinase pathway mutations to effect oncogenic transformation. Cancer Res 2008; 68: 8127-36.

38 Maruyama N, Miyoshi Y, Taguchi T, Tamaki Y, Monden M, Noguchi S. Clinicopathologic analysis of breast cancers with PIK3CA mutations in Japanese women. Clin Cancer Res 2007; 13: 408-14.

39 JIANG JK, MO WG. Mutation of PIK3CA gene and expression of AKT1/2 in human colerectal cancer and their biological significance. Guangxi Med J 2010; 32: 24-7.

40 Feinberg AP, Vogelstein B. Hypomethylation distinguishes genes of some human cancers from their normal counterparts. Nature 1983; 301: 89-92.

41 Kanai Y, Ushijima S, Nakanishi Y, Sakamoto M, Hirohashi S. Mutation of the DNA methyltransferase (DNMT) 1 gene in human colorectal cancers. Cancer Lett 2003; 192: 75-82.

42 Sardi I, Da-Canto M, Bartoletti R, Guazzelli R, Travaglini F, Montali E. Molecular genetic alterations of c-myc oncogene in superficial and locally advanced bladder cancer. Eur Urol 1998; 33: 424-30.

43 Gupta A, Godwin AK, Vanderveer L, Lu A, Liu J. Hypomethylation of the synuclein gamma gene $\mathrm{CpG}$ island promotes its aberrant expression in breast carcinoma and ovarian carcinoma. Cancer Res 2003; 63: 664-73.

44 Wang WF, He JK, Qin ZH, Wang J, Wu JC, Han R. Expressions of $\mathrm{p} 110 \alpha$ and pAKT proteins in esophageal carcinoma tissues and clinical significance. Chin J Cancer Biother 2012; 19: 539-42. 